\title{
El campo de concentración de Martín García. Entre el control estatal dentro de la isla y las prácticas de distribución de indígenas (1871-1886)
}

The concentration camp of Martin Garcia. Between state control in the island and distribution practices of indigenous peoples (1871-1886)

\section{Mariano Nagy and Alexis Papazian}

\section{(2) OpenEdition}

\section{Journals}

Electronic version

URL: http://journals.openedition.org/corpusarchivos/1176

DOI: $10.4000 /$ corpusarchivos. 1176

ISSN: 1853-8037

Publisher

Diego Escolar

\section{Electronic reference}

Mariano Nagy y Alexis Papazian, «El campo de concentración de Martín García. Entre el control estatal dentro de la isla y las prácticas de distribución de indígenas (1871-1886) », Corpus [En línea], Vol 1, No 2 | 2011, Publicado el 30 diciembre 2011, consultado el 19 abril 2019. URL : http:// journals.openedition.org/corpusarchivos/1176 ; DOI : 10.4000/corpusarchivos.1176

This text was automatically generated on 19 April 2019

Licencia Creative Commons: Atribución-NoComercial 2.5 Argentina (CC BY-NC 2.5 AR) 


\section{El campo de concentración de Martín García. Entre el control estatal dentro de la isla y las prácticas de distribución de indígenas (1871-1886)}

The concentration camp of Martin Garcia. Between state control in the island and distribution practices of indigenous peoples (1871-1886)

Mariano Nagy and Alexis Papazian

\section{EDITOR'S NOTE}

Fecha de recepción del original: 20/09/2011.

Fecha de aceptación para publicación: 12/11/2011

\section{Contextualización}

1 El registro que presentamos forma parte de la documentación interna de la Armada correspondiente a órdenes, remisión y distribución de prisioneros, listados de detenidos y correspondencia, mantenida durante el período 1870-1890, entre la Inspección y Comandancia General de Armas (en adelante ICGA) y las autoridades de la isla Martín García. Durante ese lapso, funcionó allí un centro de detención de indígenas hacia donde fue-ron confinados miles de aborígenes sometidos. Además la isla fue uno de los puntos desde donde éstos fueron repartidos a diversos destinos con el fin de utilizarlos como fuerza de trabajo en actividades productivas o en el servicio doméstico, y como soldados o marinos en el Ejército o la Armada. 
2 El acceso al material de archivo fue obtenido a través de pedidos de investigación generados en el marco del PICT-2006-0159 “Genocidio, diáspora y etnogénesis indígena en la construcción del estado Nación argentino" dirigido por la Dra. Diana Lenton. El Archivo General de la Armada (AGA) está ubicado en el barrio de San Telmo, Ciudad de Buenos Aires. Allí, personal militar y civil se encuentra abocado principalmente a la elaboración de las certificaciones de servicio del personal de la Armada que tramita sus jubilaciones, a la vez que organiza y clasifica el material de archivo considerado histórico.

3 Como resultado de nuestra labor, se ha podido obtener un importante corpus que permite caracterizar y analizar las políticas estatales implementadas con los indígenas derrotados en las campañas militares en uno de los campos de concentración que funcionaron en aquel entonces. En este caso, hemos seleccionado veintidós documentos que dan cuenta de la circulación de los vencidos desde la ciudad hacia la isla, las prácticas de control y disciplinamiento en la isla y el repartimiento desde el punto hacia distintas regiones del país.

4 El AGA posee en guarda estos documentos porque Martín García funcionó bajo una doble jurisdicción entre la provincia de Buenos Aires y la Armada. En 1854 tras la secesión de la Confederación Argentina, Buenos Aires la incluyó en su Constitución como parte del territorio bonaerense, pero al tratarse de una isla, la Armada tuvo una plaza militar de manera constante hasta la recuperación democrática de 1983, cuando Buenos Aires volvió a detentar su usufructo, y la incorporó como parte del municipio de La Plata. Esto explica la importancia del AGA para la obtención de fuentes acerca de las políticas implementadas con los indígenas en la segunda mitad del siglo XIX.

Para la búsqueda de información se ha seleccionado el período transcurrido entre $1870 \mathrm{y}$ 1890, en función de incluir la intensificación del hostigamiento para el corrimiento de la frontera una vez finalizada la Guerra del Paraguay (de Jong 2005, 2007; Nagy 2010; Papazian 2010), con especial énfasis en la Conquista del Desierto (1879-1885), y continuando el relevamiento de los años posteriores a las campañas militares de Pampa y Patagonia e inicios de las campañas al Chaco, con el objetivo de observar y analizar los cambios y continuidades en el modus operandi del centro de detención de indígenas de la isla.

6 El edificio del AGA cuenta con varios pisos pero sólo se permite el acceso a la planta baja, donde existe un escritorio en el cual se deposita la documentación previa-mente requerida por los investigadores. El material está agrupado en cajas de madera. Cada una de ellas contiene diversa documentación referida a una plaza militar específica y a un año específico, únicos criterios de clasificación y separación. Es decir, cada caja suele contener la documentación de un determinado lugar y año, cada caja posee un número asignado. En general, los dos últimos dígitos de dicha numeración se ajustan al año de elaboración de las fuentes. Así, por ejemplo, la caja 15279 guarda información sobre 1879.

7 La mayor parte de la documentación se compone de órdenes emitidas por la ICGA; de listados de uniformes para los oficiales y de personas detenidas o remitidas; y de actas de defunción y de correspondencia entre las autoridades de Martín García y la ciudad de Buenos Aires. Excepcionalmente se han encontrado sumarios judiciales, algunos croquis de la isla y cartas que los detenidos escribieron a sus familiares, pero que nunca fueron despachadas, ya que si así fuera, no estarían en guarda en el archivo.

8 En algunos casos se consigna la procedencia indígena de las personas referidas, en especial cuando se confeccionan listados o se indica remitirlos hacia o desde Martín 
García, aunque este tipo de registro no parece ser un lineamiento sistemático, sino más bien un criterio de quien imparte la orden o escribe la correspondencia.

\section{Explicitación}

Para acceder al material del AGA, es condición indispensable contar con la aprobación del Estado Mayor de la Armada, organismo que previamente exige presentar de manera escrita, información acerca de los investigadores. En la solicitud deben detallarse los datos personales de quiénes realizarán la labor y describirse la pertenencia institucional, la temática y los objetivos pretendidos en la pesquisa. En este caso en particular, tras meses de espera, un funcionario castrense informó la aprobación y nos remitió a Casa Amarilla, sede de Estudios Históricos de la Armada y lugar de acceso irrestricto. Allí, las autoridades nos comunicaron que desconocían nuestro pedido de ingreso al AGA, pero que podíamos acceder a las de-pendencias de Casa Amarilla. Por tanto, elevamos nuevamente la solicitud de aprobación al Estado Mayor, además de realizar llamadas semanales para conocer el estado de nuestro pedido.

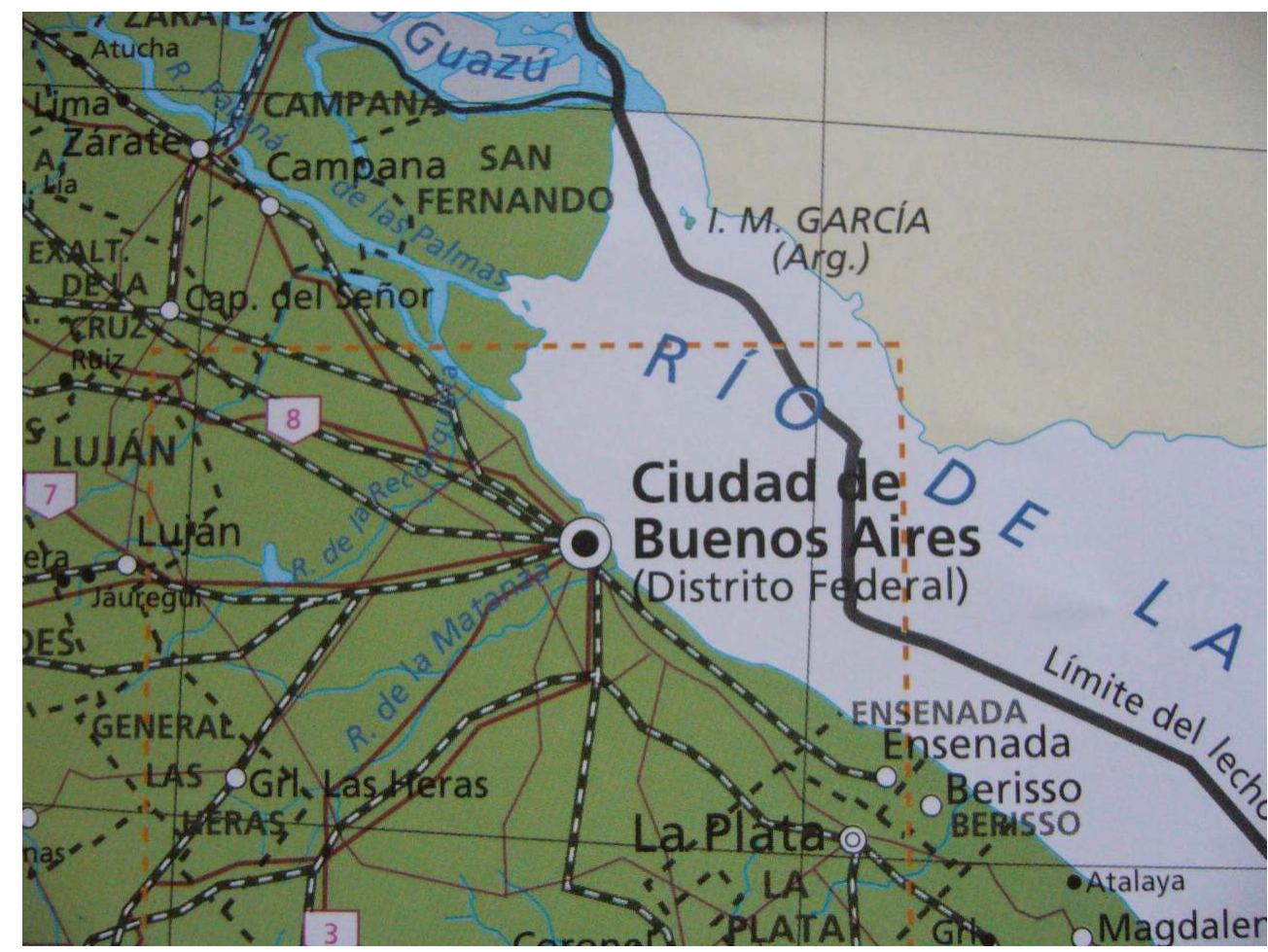

MAPA 1. ISLA MARTÍN GARCíA EN REFERENCIA CON LOS LÍMITES ARgENTINo y URUgUAYO.

Luego de varios meses de iniciado el trámite, se aprobó el ingreso y la primera cita en el AGA. El jefe del archivo, el Mayor Riveros, comunicó las condiciones para trabajar: Reservar turno para no superponerse con otros académicos y asistir regular pero espaciadamente para no entorpecer la labor del personal civil (una vez por semana). Una vez establecidos en el único escritorio disponible, una empleada nos brindó una serie de documentos que fue previamente seleccionada y separada para nuestro uso, elegida de acuerdo a los temas a investigar que fueron descriptos en la petición formulada para ingresar al AGA. Dicho compendio pertenecía a distintas cajas, y una vez concluidas se nos autorizó a que solicitáramos de a tres cajas por vez para su revisión total. Ese fue el procedimiento que se siguió a continuación, y siempre, antes de retirarnos del lugar 
debíamos avisar qué día de la siguiente semana regresaríamos, información que se anotaba en un cuaderno. A partir de esta dinámica, el proceso de revisión, consignación, transcripción y fotografiado de fuentes se extendió por casi un año, desde noviembre de 2008 hasta agosto de 2009.

11 El material aquí publicado solo compone una muestra de una gran cantidad de fuentes. El método de relevamiento consistió en revisar documento por documento, entre ambos investigadores y de a una caja por vez. Desde un principio se realizó una búsqueda que adoptó un criterio simple: transcribir y fotografiar todo papel que hiciera mención a indígenas, sean éstos cautivos, próximos a remitirse hacia la isla o prontos a distribuirse desde ese punto hacia otro destino. También se incorporó material que, sin apelar directamente a los aborígenes, se considerara pertinente o plausible de estar relacionada con ellos. Además se tuvieron en cuenta datos, normativas, disposiciones o leyes referidas a Martín García que permitieran contextualizar las fuentes. Así, entre otros datos, se consignó la decisión de fortificación de la isla, la instalación del correo, de la escuela y del lazareto; el pedido de financiamiento y personal para nuevas construcciones y las comunicaciones de cambio de autoridades.

Para ello, se confeccionó un listado con la siguiente información: Número de orden y de foto, Descripción, Caja, Fecha y en el caso que figurara, Firma. Así a cada foto se le asignó un número y una descripción que posee su correlato en una lista descriptiva de imágenes y documentos. De este modo se labró una planilla con alrededor de 500 documentos.

13 El criterio de selección de toda esa información, está ligada a dos ejes fundamentales: 1) El traslado, clasificación y circulación de indígenas por la isla y 2) La distribución de indios presos hacia otros pun-tos de la Argentina.

Desde una perspectiva total de la documentación obtenida, se percibe una repetición de órdenes, avisos o listados, como pueden ser actas de defunción, listas de vestuario y racionamiento; y remisión de indígenas a la isla. La idea de priorizar una decena de fuentes de cada eje (Traslado hacia y distribución desde la isla) se basa en dos características yuxtapuestas que conforman el modelo de detención, confinamiento y reparto de indígenas llevado a cabo en la isla Martín García durante el proceso de organización nacional y de realización de las campañas militares para el sometimiento de los pueblos originarios.

Por un lado, se presentan aquellas fuentes que a partir de su reiteración a lo largo de todo o gran parte del período abordado, constituyen un ejemplo del proceder sistemático por parte de las autoridades militares con los indígenas sometidos, en ese contexto y para el caso de Martín García. Por otro, se publica cierto material que representa alguna particularidad que la torna excepcional por el destino dispuesto, la característica de la orden emitida o la información que brinda para la comprensión del procedimiento aplicado, sin excluir en ambos casos, sus aportes para reflexionar acerca de las políticas estatales frente a los sectores percibidos como "otros" y/o disruptivos del orden social que se pretendía establecer en la Argentina de fines del siglo XIX.

\section{Breve ubicación geográfica e histórica de la isla}

Martín García se encuentra en cercanías de las costas uruguayas y a unos 40 kilómetros de las playas argentinas. En tiempos coloniales fue disputada por España y Portugal. Desde la segunda mitad del siglo XVIII funcionó en la isla el presidio, luego una guarnición militar 
con canteras de piedra y arena. Poco después de la Revolución de Mayo de 1810, el almirante Guillermo Brown derrotó a los realistas españoles y ocupó la isla a favor de Las Provincias Unidas del Río de la Plata. En 1817 llegaron los primeros presos políticos del periodo independentista. En los años siguientes Martín García fue disputada con Brasil y con Uruguay siendo ocupa-da durante los bloqueos anglo-franceses llevados a cabo en contra del Gobernador Rosas. En 1854, tras la caída de Rosas, y la separación de Buenos Aires de la Confederación Argentina, la isla queda bajo la jurisdicción bonaerense (Kröpfl 2003, p. 43). ${ }^{1}$

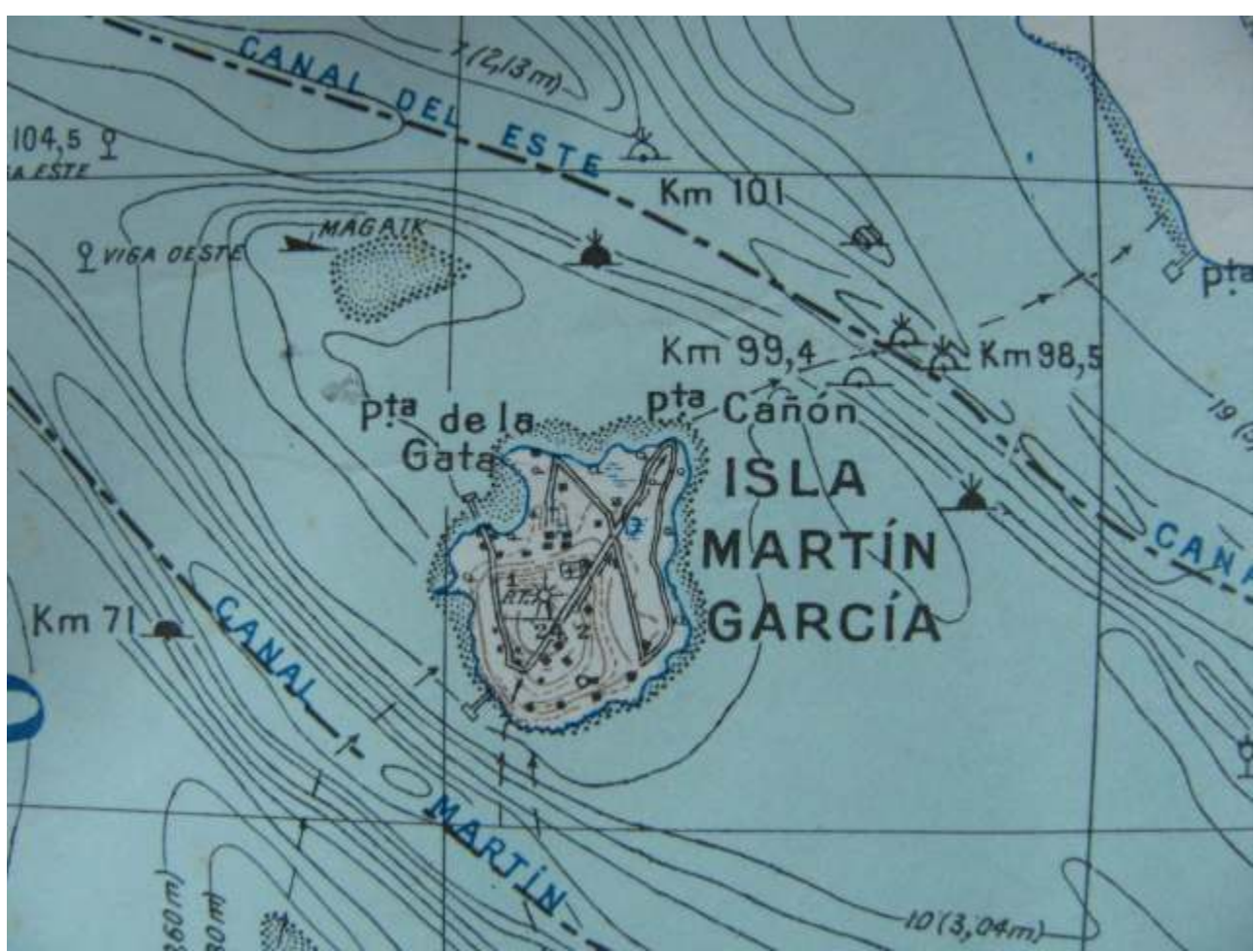

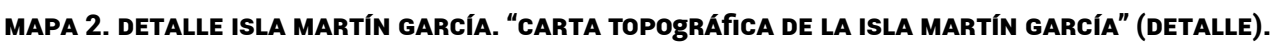
HOJA 3657 INSTITUTO GEOgRÁfiCo MILITAR. BUENOS AIRES. 1943.

Su tamaño es de 180 hectáreas y está localizada levemente hacia el sur de la estratégica confluencia de los ríos Uruguay y de la Plata Como se ha mencionado si bien en términos jurisdiccionales estuvo bajo la órbita de la provincia de Buenos Aires, la Armada (Marina) Argentina hizo uso y posesión cuasi-exclusiva sobre Martín García (prisión militar, cuarteles, escuela de conscriptos, hospital militar, etc.), hasta que, tras la última dictadura cívico-militar, devolvió la posesión de la isla a la provincia.

En 1989 se sancionó la Ley 12.103 declarándola Reserva Natural de Uso Múltiple en el marco de la Ley de Reservas y Parques Naturales provinciales y del Tratado internacional del Río de la Plata. ${ }^{2}$

\section{El sometimiento indígena}

Desde la realización de la Conquista del Desierto (1878-1885) y durante gran parte del siglo XX, fue dominante la idea de la extinción del indígena como consecuencia de las campañas militares comandadas por Julio Argentino Roca. En el imaginario colectivo de los argentinos, tanto desde una perspectiva celebratoria de las mismas como desde ciertos 
enfoques críticos, la consecuencia mayor-mente difundida y aceptada fue la desaparición del indígena a partir del enfrentamiento bélico con las tropas militares.

Estas construcciones historiográficas invisibilizatorias entran en relación con la propia construcción de la matriz Estado-Nación-Territorio y con las políticas reales llevadas adelante contra la población indígena en Argentina. Estas abarcaron una amplia gama de estrategias "civilizadoras" que tendieron a desestructurar, reducir, someter, incorporar y/o eliminar la presencia indígena en el imaginario identitario argentino (Briones y Delrio 2002; Mases 2010; 2002; Delrio 2005; Lenton 2005; 2007).

Diferentes estudios, algunos centrados en la "cuestión indígena" (Mases 2002; Sosa 2001) o en la historia de Martín García (Kröpfl 2003; Fitte 1971), mencionan a la isla como un espacio de reclusión de caciques, capitanejos y sus familias; otros trabajos hacen mención de ese espacio en función de análisis específicos sobre el devenir de "caciques" y "capitanejos" (Hux 2003a [1991], 2003b [1991], 1991).

Paralelamente diferentes investigadores califican la expansión estatal y la conquista de las sociedades indígenas como parte de un proceso genocida que se observa en la sistematicidad por la cual el Estado genera prácticas “... con la intención de destruir, total o parcialmente, a un grupo nacional, étnico, racial o religioso...”3 (Añón, Pepe y Harrison 2009; Bayer, 2010; Delrio y Escolar 2009; Delrio, Lenton, et. alt. 2010; Musante 2009; Pérez 2007; RIG 2008; Trinchero 2005; Valko 2010). Sin embargo, tenemos en cuenta la pertinencia en el uso del término etnocidio o genocidio cultural si circunscribimos nuestro análisis a las prácticas que operan de manera exclusiva al interior de la isla. En otras palabras, si el campo de concentración de Martín García fuese el único registro vinculado con la eliminación y el sometimiento de indígenas, entonces, podríamos entender que el Estado llevó adelante un etnocidio; en cambio, si observamos el proceso a nivel general -campañas militares, fusilamientos, deportaciones, desmembramientos de familias y confinamientos, entre otras medidas, entonces estamos ante un genocidio. Nuestra mirada es global.

Este punto de partida nos permite enmarcar y categorizar las prácticas concentracionarias llevadas adelante en Martín García como parte de un proceso genocida.

El aporte de este artículo no se enmarca en el debate específico sobre la forma de categorizar y repensar el proceso de expansión estatal, sino que se basa en trabajos anteriores, algunos realizados dentro de los proyectos de investigación que integramos ${ }^{4}$, para dar cuenta de una parte específica de este proceso genocida. Es decir, lo que busca este artículo es poner en relevancia la importancia de un campo de concentración (como el de la Isla Martín García) en el contexto de expansión estatal y sometimiento indígena.

Gracias a las fuentes consultadas relevamos más de 500 documentos en los cuales se mencionaban la "entra-da" y "salida" de indígenas, así como también las directrices a seguir sobre los mismos, una vez que estaban en la isla (Nagy y Papazian 2009; Papazian y Nagy 2010)

Estas fuentes nos permitían analizar la sistematicidad e intencionalidad genocida, entendiendo, en consonancia con la línea teórica de Giorgo Agamben (1998; 2004), al campo de concentración como un espacio cuyo objetivo es regular la vida de las víctimas (y su disponibilidad como cuerpos). Partiendo de esta definición y del trabajo documental observamos la validez de pensar en el campo de concentración. En este punto es necesario remar-car la taxonomía variada con la que los indígenas eran llevados y registrados en la 
isla, ya que suelen revistar como presos por su condición de "indios" (AGA Cajas 15272-15286; Copello 1944). Es su exterioridad indígena la que regula las normas de encierro. Siguiendo a Agamben observamos el nexo entre el:

estado de excepción y campo de concentración... La novedad es que esta institución (el campo) se desprende del estado de excepción sobre el cual se fundaba y se la deja devenir en la situación normal. El campo es el espacio que se abre cuando el estado de excepción comienza a devenir la regla. En ese momento, el estado de excepción, que era esencialmente una suspensión temporal del ordenamiento, adquiere un orden especial permanente que, como tal, permanece, sin embargo, constantemente fuera del ordenamiento normal" (1998, p. 53).

El campo (de Martín García) se entiende como un "devenir excepcional-normal” por fuera del ordenamiento institucional que rige al Derecho; la isla se conecta con la praxis genocida en una coyuntura histórica de conformación y constitución estatal (Feierstein 2007, p. 97-101). Bajo esta coyuntura, observamos la importancia de los documentos aquí trabajados. Documentos generados por y para la institución militar que refieren a normas y órdenes particularísimas que se explican sólo por la excepcionalidad en la cual el sujeto indígena es construido desde el Estado.

\section{Registros sobre la explotación laboral y el disciplinamiento}

El siguiente apartado describe y analiza fuentes históricas relativas a las formas de control, disciplinamiento y explotación física de los indígenas concentrados en la isla Martín García hacia finales del siglo XIX. Esto nos permite observar la cotidianidad en la isla y algunas características específicas de este campo. Partimos de la conceptualización de campo mencionada en el apartado anterior teniendo como eje, que estos espacios de con-trol sobre los cuerpos disciplinan a partir de una inicial deshumanización del grupo social recluido para luego rehabilitarlo, siempre parcialmente, como "cuerpo" humanizado y útil. Este sistema excepcional, pero norma-do, debe ser comprendido como una política más dentro de un proceso genocida a escala nacional que buscó eliminar física y simbólicamente al indígena.

31 En lo referido a la isla, los documentos aquí transcriptos dan cuenta de un espacio de control que no está específicamente con el exterminio físico de indígenas (Valko 2010) ni con el de una prisión regular (Mases 2002). Así entendido y circunscribiendo el análisis a la situación específica de Martín García, podría objetarse la utilización del concepto genocidio a favor del de etnocidio o genocidio cultural ${ }^{5}$. Sin embargo, lo que puede parecer preciso para explicar el caso específico de Martín García resulta insuficiente al inscribir dicho caso en un proceso de mayor amplitud y escala como fue el de la Conquista del Desierto. Por ello, desde una perspectiva que contempla el proceso general del sometimiento indígena en el marco de la consolidación del estado nación, optamos, como Lenton (2010), por encuadrar las políticas indígenas estatales dentro de la definición de Genocidio de sanciona-da por la ONU en 1948.

En ese contexto inscribimos a la isla como una pieza que compone al proceso genocida, entendiéndola como un campo de disciplinamiento de indígenas bajo la órbita del Estado, en particular de la Armada. Con esto no negamos la gran cantidad de indígenas allí fallecidos (AGA Cajas 15277 y ss.; Archivo del Arzobispado de Buenos Aires; Valko 2010; 
Kröpfl 2003; Copello 1944) ${ }^{6}$; ni el funcionamiento regular de la prisión que existía en Martín García; en tanto observamos por medio de la documentación trabajada, la práctica sistemática en pos de destruir:

las relaciones sociales de autonomía y cooperación [como]... la identidad de una sociedad, por medio del aniquilamiento de una fracción relevante (sea por su número o por los efectos de sus prácticas) de dicha sociedad... para el establecimiento de nuevas relaciones sociales y modelos identitarios" (Feierstein, 2007, p. 83).

Esta sistematicidad se traduce en formas disciplinarias en las que “...el dominio social se construye a través de una red ramificada de dispositivos o de aparatos que producen y regulan costumbres, hábitos y prácticas productivas" (Hardt y Negri, 2000, p. 25). Foucault observa la acción disciplinaria sobre los "... cuerpos sometidos y ejercitados, cuerpos 'dóciles'...” (1976, p. 141-142) sobre los que el Estado ha “...tomado a su cargo la vida y, más que la amenaza de asesinato, dio al poder su acceso al cuerpo" (1987, p.172-173).

La circulación de los indígenas por diferentes repartimientos instalan, la "...constitución (del cuerpo) como fuerza de trabajo..." a partir de "un sistema de sujeción...” donde "...el cuerpo sólo se convierte en fuerza útil cuando es a la vez cuerpo productivo y cuerpo sometido" (1976, p. 32-33). El Anexo 1 de este artículo transcribe documentos que explican de manera clara la llegada y el accionar disciplinario de estas instituciones; en el Documento 1, producido por la ICGA se menciona la llegada de "cincuenta y dos Indios y cinco familias, cuya lista se acompaña, que han sido destinados á los trabajos de esa Isla hasta nueva disposición...". La lista "nominal de los indios y familias" es confeccionada en el Batallón $3^{\circ}$ de Línea donde estaban "en depósito".

Observamos aquí cuestiones que dan sentido a nuestro análisis en torno a la isla como campo de concentración: el origen de estos indígenas (el Batallón $3^{\circ}$ de Línea) indica un previo sometimiento y clasificación en donde estaban sometidos; el uso del término "depósito" no sólo indicaría un lugar físico, sino condición de disponibilidad ante las tareas requeridas. Este tipo de clasificación se repite en la isla, donde serán consignados como indios inútiles, de depósito, o presos, dependiendo del estado de salud con el que ingresen, el sexo, la edad o el grado de peligrosidad consignado por la fuerza militar. De igual manera los nombres que se imponen a los indígenas sometidos es en sí mismo un tópico de estudio en relación con las prácticas de disciplinamiento y control. En la lista detallada en este documento la mayor parte de los nombres (45 sobre 52 ) son apellidos y/ o nombres de origen español; al igual que el de las "familias" se corresponden sólo a nombres de mujeres, también con nombres españoles (a excepción de uno). Por otro lado se ignora la cantidad de niños reducidos en la isla, pero se percibe que los mismos irían dentro del contingente de familias. Con respecto a la imposición de nombres europeos en "reemplazo" de los nombres nativos, observamos que dar nueva identidad al contingente reducido niega, en buena parte, su existencia como tales. Tal política no se reduce a un momento y espacio específico si no que determina un modelo de identidad nacional que opera hasta nuestros días.

En tal sentido Morita Carrasco menciona que el desconocimiento en torno a la cantidad de población indígena que habita en el territorio responde al:

relativo éxito alcanzado por el esfuerzo que los dirigentes políticos realizaron para demostrarle al mundo que Argentina es un país blanco y culturalmente homogéneo... Esto nos remite a una situación de privación de la identidad que ha 
llevado - y lo sigue haciendo- a que muchos indígenas negaran su pertenencia étnica..." (2000, p. 7). que aquejan a los indígenas. ${ }^{7}$ Entre las prácticas llevadas adelante en Martín García podemos observar los informes del cirujano Sabino O'Donnell sobre indígenas "inútiles" reclutados en cuerpos militares. En los tres documentos aquí transcriptos se mencionan la utilidad o inutilidad de los cuerpos en relación con las tareas asignadas en la isla; así como el trato a seguir sobre los mismos. El Documento 3 indica, sobre un listado de indígenassoldados que los:

mencionados no podrán seguir prestando el buen servicio que se requiere en su puesto; y el Gefe del Batn. ha adquirido sus duda la prueba práctica de esto, cuando solicito la baja de estos individuos... e incurables, que no podrán mejorar su estado de situación por mas que se haga.

médico juzga que el mejor destino de estos individuos podrá ser un buen... con la atención y el mejor que se seguire. Si bien podrán alguno de ellos prestar servicios mecánicos en el Cuartel."

41 El mismo cirujano pide se le haga entrega de los elementos necesarios para poder llevar a cabo su labor médica (Véase Documento 4) y detalla de sus experiencias como profesional ante el arribo de 148 indígenas, informando:

...concluí de vacunar a todos los indios del depósito [...] Indudablemente venían ya impregnados o contagiados. Al vacunarlos se ha desarrollado la epidemia entre ellos, llegando hoy el número de virulentos a once, de los que fallecieron dos hoy temprano. Se creía que la vacunación hubiera influido en la propagación y aumento de los enfermos, pero semejante opinión solo la ignorancia puede abrigar.

Es llegado el momento de contestar una de las consultas que se me ha escrito V.S dirigiendomé respecto al travajo de estos Indios, y á los males que pueda causarles. El travajo pesado y laborioso no podrá menos que ser nocivo a muchos de ellos. El indio es flojo y acostumbra-do al ocio. Todo esfuerzo es para él estraordinariamente penoso y en la estación en que estamos, en la debilidad en que se hallan los más, por 
su falta de buena alimentación, en las penurias que viven padeciendo; el abatimiento moral, pues sienten ellos la pérdida del desierto como puede sentir un Rey la de sus palacio; y además, la enfermedad que va tomando crecer, todo esto aconseja la mayor moderación en el trabajo.

Pero es preciso al huir de un estremo, no caer en otro, tanto o más peligroso q el ecceso de travajo. [...]

No conviene que estos hombres estén encerrados, aglomerados, y sin movimiento, en esa actitud ó manera de ser ellos, q pasan 24 horas y aún más, tirados en su mala causa. [...]

Es preciso sacarlos al aire libre y aún obligarlos a hacer un poco de ejercicio.

No me atreveré a indicar a V.S otras medidas de higiene de aseo en sus habitaciones, ropas y camas, corte de cabello q todos llevan crecidísimo y demás cuidados que son demasiado vulgares por q temeria hacer una ofensa. (Documento 5) y prescripción, marcan la relación entre diferentes prácticas higienistas, con problemáticas cotidianas y fines utilitarios sobre los indígenas allí recluidos. Además plantea, desde la mirada del mismo médico, los efectos devastadores generados por el traslado y concentración en Martín García que generan "el abatimiento moral, pues sienten ellos la pérdida del desierto como puede sentir un Rey la de sus palacios" sin por eso dejar de lado las críticas a las formas de vida tradicional de las parcialidades originarias a las que cataloga, como mínimo, de ociosas. El importante brote de viruela está vinculado con la deportación y el encierro. Esta situación es documentada como un verdadero problema para las autoridades (militares y eclesiásticas); pues no es la eliminación física lo que se busca, si no la salud física y espiritual a partir de la pérdida de "atributos bárbaros" para la posterior utilidad en tanto indígenas sometidos y civilizados. Con respecto a las labores dentro de la isla, observamos que las mismas varían y son sumamente amplias. Así, los indígenas incorporados tanto al Batallón Artillería de Plaza como al Piquete Guarda Costa, ambos cuerpos militares que funcionan dentro de la isla (véase Documento 6, 7 y 8) operan como instituciones de control y vigilancia hacia otros indígenas y prisioneros. Al respecto vale observar la repetición de material referido a la entrega de vestimenta militar para los indígenas recluidos en la isla, situación que se explicita en el Documento 6, pero que se observa de manera repetitiva en diferentes papeles del AGA.

Dichos cuerpos son pensables como verdaderos espacios de "normalización" para los propios indígenas que revisten en ellos; observando este importante punto, ya que muchos de los indígenas reducidos en estos espacios, pasarán (como veremos en el siguiente apartado) a diferentes cuerpos del Ejército y la Armada fuera de Martín García. Ahora bien, la forma de incorporación de indígenas a las armas parte del sistema concentracionario que funciona en Martín García. El Documento 7 da autorización al pedido del Coronel Matoso de:

reemplazar con los indios presos las bajas ocurridas por di-versas causas en el Piquete "Guarda Costa", de esa Guarnición, hasta reintegrarlo en su fuerza primitiva,... Constando el Piquete "Guarda Costa", de un sargento y veinte nueve soldados queda usted autorizado para dar el alta de la forma indicada doce indios de los que existen allí presos."

Se observa como la clasificación inicial con la que los indígenas son ingresados a la isla podrá variar dependiendo de la necesidad existente en dicho punto, sin embargo, la queja del Comandante Nelson (Documento 8) revela los límites y las contradicciones con las que se encuentra la superioridad: 
el personal del Batallón de Artillería de Plaza es insuficiente para llevar debidamente el servicio (...) pues sus dos terceras partes son indios sacados de entre los mismos que están con la denominación de presos y las guardias de los polvorines, de los galpones donde se alojan los indios y chinas y del Puerto Viejo son montadas sin oficiales, por la carencia de ellos, pues sólo hay presentes cinco en el Batallón, de estos, uno está encargado de la mayoría, otro desempeña las funciones de ayudante, y un tercero es habilitado de la guarnición, (...) las guardias están a cargo de clases indios, que son también los soldados en su mayor parte; siendo los cuidadores y cuidados de la misma raza, una misma familia, se puede decir; los oficiales de la Plana Mayor de esta Comandancia son pocos para el servicio de campo y demás que hay que desempeñar diariamente; la Subprefectura de Marina no está en mejores condiciones para llenar su cometido pues solo tienen seis marineros, siendo de es-tos dos indios y en su totalidad poco tienen de marineros, sería el nombre subordinado o cual cosa con los oficiales subalternos, que son inapropiados marineros. Con semejante personal, Señor Comandante General, no será extraño que se repitan casos como el que hoy dí cuenta a V. S. por telegrama. Por las razones espuestas verá V. S. que es de urgente y suma necesidad mejorar y aumentar el personal de la Guarnición de esta Plaza dando altas cristianas y más oficiales... dada por las propias condiciones naturales de la isla y el constante arribo de indígenas 
concentrados en ella. Particularidad generada a partir de esa relación de extrañeza que opera sobre los indígenas desterrados y que oficia per se como un gran espacio concentracionario. Al respecto vale la pena recordar que se deportan a la isla indígenas "presos", indígenas para el "depósito", indígenas mujeres ("chinas") y niños ("criaturas") que son ingresados como cuerpos disponibles tanto para las necesidades propias de la isla como para las necesidades de otras instituciones estatales y/o privadas que operan desde fuera de la isla (Nagy y Papazian, 2009; Papazian y Nagy, 2010).

A modo de nexo entre el tópico aquí analizado y del apartado siguiente, el Documento 11 nos permite ver observar otro tipo de circulación, el que va de la isla a la Capital. Es así que desde la Intendencia y Comandancia General de Armas (ICGA), el General Luís María Campos ordena al Coronel Donato Álvarez que "se reciban en depósito en esa isla, los indios y chusma que conduce el vapor 'Santa Rosa"' a la vez que pide que "En el mismo vapor... [remitan] todas las indias mujeres y chusma de los que anteriormente se mandaron a su parte, que se encuentran en condiciones de venir a esta Ciudad.". Siendo registrada la llegada de "... 98 indios, 120 chinas y 131 de chusma", a la vez "... que se remiten a la Capital 63 chinas y 35 criaturas de las que se encontraban en depósito”. Esta "entrada" y "salida" de indígenas vuelve a marcar uno de los puntos iniciales por los cuales caracterizamos a este campo de concentración, como un campo de disciplinamiento y control sobre los cuerpos. Hecho que no hace menos genocida al proceso, pero sí muestra variables específicas en este tipo de crímenes donde el exterminio no se limita a la eliminación física.

\section{Registros en torno a la práctica de repartimiento de indígenas}

En este apartado se presentará un material que permite establecer la existencia de un plan sistemático de reparto de prisioneros destinados principalmente a actividades productivas, servicio doméstico e incorporación al ejército y a la marina. A partir de la lectura de estos documentos (véase Anexo 2) se observa la continuidad entre las prácticas de control y explotación en la isla, con las prácticas de distribución y utilización fuera de la misma. Martín García es, entonces, un sistema concentracionario y dinámico que tuvo como objetivo la utilización de los indígenas tanto dentro como fuera de la isla. Como hemos mencionado, la circulación de los indígenas por diferentes instituciones disciplinarias (la prisión, el depósito, la escuela, el lazareto, las canteras, el Ejército, la Marina, la Iglesia, el hospital, etc.) (des)humanizan al indio y lo convierten en fuerza de trabajo, lo que lleva a la categorización de la isla Martín García como un campo de disciplinamiento y no de exterminio, donde se impulsó el reparto de "cuerpos disponibles" como política de Estado. Su implementación se dio a través de prácticas que generaron la desarticulación de las comunidades y las familias, su sometimiento y su incorporación forzada, en la mayoría de los casos, de manera individual y ocasionalmente familiar.

51 Al ingresar a la isla, los indígenas eran categorizados según su utilidad para el trabajo, de modo que aquellos aptos para tal función eran ingresados como "indios presos" y los que no se encontraban en condiciones eran calificados como indios de o en "depósito". Sin embargo esta diferenciación no era definitiva, dado que no pocas ocasiones éstos últimos 
eran trasladados hacia distintos puntos del país o integrados a las incipientes Fuerzas Armadas.

El acopio y el análisis de cada una de las esquelas, órdenes y listas referidas a la repartición de prisioneros, da cuenta de las alternativas y variantes posibles al momento de pensar en los destinos de los sometidos, y toma mayor dimensión, al abordarlos en forma conjunta como un corpus que, de manera transparente e inequívoca, refieren a una estrategia pensada previamente y ejecutada de manera sistemática.

Cada una de las breves notas que en general, no exceden la carilla, va construyendo la trama de un plan sistemático, con sus diversos destinos en cuanto a su funcionalidad y lugar de llegada. Cada indio distribuido constituye un hilo de un ovillo difícilmente cuantificable, pero que tomado en su conjunto evidencia la puesta en disponibilidad de los indígenas como fuerza de trabajo esclava a favor de las elites y ciertas instituciones argentinas.

54 Entre los apropiadores beneficiarios que recibieron indígenas, la documentación no siempre consigna el nombre, sin embargo aparecen autoridades militares importantes, políticos y miembros del poder judicial. En algunos casos se demuestra que para acceder a la obtención de algunos sometidos, era necesario tener algún contacto o relación con miembros de la jerarquía militar. Esto se observa en algunos documentos que disponen la entrega de indígenas al portador de una carta firmada por la superioridad. Algunas crónicas periodísticas de la época daban cuenta de este procedimiento: "el cronista describía cómo personas con cartas procedentes del Estado Mayor del Ejército, reclamaban uno o dos indios, antes de que estos desembarcaran y les eran entregados de inmediato..." (Diario La Nación 31/10/1885, en Mases 2002, p. 97). Este procedimiento puede ser corroborado en el documento 12, de marzo de 1879: "Sírvase usted disponer le sea entregado al portador de la presente al indio Jacinto Segundo Puelpan que existe en depósito en esa isla"

Es difícil establecer el inicio del sistema de distribución, aunque por el material existente pareciera que el punto más álgido tuvo que ver con la avanzada final de la frontera en la última parte de la década de 1870. Durante las importantes y continuas incursiones previas, y el propio comienzo de la Conquista del Desierto, precisamente en los 1878 y 1879, se constata una mayor documentación sobre la circulación de indígenas deportados hacia la isla y desde allí hacia distintos puntos de la Argentina. Sin embargo, ya en los albores de esa década se encuentran solicitudes de confección de listados de indígenas confinados en la isla ${ }^{10}$ y en 1872, traslados de indígenas desde Martín García a los cuarteles de Retiro, en algunos casos para ser enrolados en el ejército: "Se ha recibido la nota de usted..., en la que dice... remite al Cuartel del Retiro de esta ciudad, los once indios que se le ordenó. En contestación se dice a usted que han sido recibidos los indios..." (Documento 13). La documentación del AGA permite establecer la continuidad de una política de reparto de indígenas, dado que una década y media después de los primeros registros sobre envíos de nativos a la isla y de los tempranos repartos de indios prisioneros (1871-1872), y ya finalizadas las campañas militares en Pampa y Patagonia (1885), el propio Coronel Rudecindo Roca logra que en 1886 le remitan un contingente de indios presos: "Se ha resuelto sean entregados al Sr. Gobernador del Territorio de Misiones Coronel Don Rudecindo Roca los indios con sus familias que se encuentran en la isla de Martín García y que han revistado hasta ahora en calidad de indios presos" (Documento 14) 
De la lectura de las cartas de solicitud de indios se desprende que para algunos miembros de las clases dominantes, ser favorecidos con unos cuantos indígenas no era una meta difícil de conseguir, en tanto sus pretensiones son minuciosas y precisas, consignando cantidad de individuos o familias, edades y sexo de los sometidos que desean obtener. Evidentemente, esto era factible debido a que no se denegaba ningún pedido y las distintas personalidades que recurrían como beneficiarios del sistema de distribución sabían fehacientemente que se trataba de formular las exigencias y esperar a que las autoridades militares concretaran sus deseos de ampliar el personal con los derrotados de la Conquista del Desierto.

Así ocurre con Carlos Casares, gobernador de la provincia de Buenos Aires entre 1875 y 1878, y con el juez Gregorio Torres. Incluso en su anterior pedido de once indígenas, el magistrado ya había recibido quince nativos, cantidad compuesta por indios, chusma y criaturas:

Sírvase usted disponer sean entregados al Señor Don Gregorio Torres... once indios de los existentes en esa isla, con sus mujeres respectivas e hijos. Firma Luís María Campos.

[Sobre el margen izquierdo de la orden]: En marzo 13 se entregaron al apoderado del Dr. Torres 4 indios, 4 chusmas y 7 criaturas" (Documento 15)

Sirva usted disponer le sean entregados al portador de la presente diez familias indígenas compuesta del indio, china e hijos debiendo la que no tenga marido ponerlo de los que revisten en la isla, mayores de 40 años, los cuales son ocho para Don Gregorio Torres y dos para Don Carlos Casares" (Documento 16)

Es de destacar la funcionalidad que podría tener un núcleo familiar o más bien un grupo conformado por un hombre, una mujer y los niños. Como puede observarse en el pedido de familias indígenas para Torres y Casares, las mismas debían estar compuestas por indio, china e hijos, y cuando las mujeres no tuvieran pareja, se agregaría un varón de los indios mayores de la isla que superaran los 40 años. De modo que se impulsaba el ensamble de grupos que contuvieran a su interior un hombre, una mujer y niños, sin importar la filiación y la organización indígena, y seguramente con la intencionalidad de atribuirle una tarea distinta a cada uno de ellos.

El material que se encuentra en el AGA no sólo echa luz sobre los distintos derroteros impuestos a los vencidos, sino también, dada la multiplicidad y variedad de posibles destinos, pone de manifiesto la imposibilidad de dar cuenta de todos ellos. Como se ha mencionado, la documentación es profusa y en ocasiones hay reiteración de trayectorias y puntos de llegada, sin embargo no escasean aquellas órdenes que señalan un rumbo nunca antes mencionado. Este aspecto permite dimensionar los alcances del reparto de indígenas, dado que las fuentes revelan el funcionamiento, durante varios años, de una política de concentración, disponibilidad y entrega de los indios sometidos, que los distribuyó en condiciones de esclavitud a lo largo y a lo ancho de del territorio nacional argentino recientemente construido y consolidado.

Por caso, un documento de 1884 menciona como destino a los talleres de marina del Tigre, localidad ubicada en la zona norte de la provincia de Buenos Aires, un lugar que no vuelve a aparecer en el resto del material estudiado para el período 1870-1890:

Con esta fecha se ha dispuesto que usted proceda a remitir a la mayor brevedad, con destino a los talleres de Marina del Tigre, a los indios Benito, Piní y Bartolo y su mujer Juanita con una chiquita de año y medio, que existen entre los que se encuentran al servicio de esa isla" (Documento 17) 
61 No puede establecerse si los talleres del Tigre representan un excepcional ámbito de recepción o uno habitual sobre el cual no consta material. De todos modos, nuevamente el pedido es explícito en cuanto a la cantidad de personas a entregar, a lo que se agrega un elemento que no suele aparecer en forma recurrente, la mención de los nombres de los trasladados. Si bien no es el único caso en el cual se consignan la denominación o seudónimo de los indígenas, en general es más frecuente cuando se trata de un cacique o capitanejo y bastante más común cuando existe una intervención de las autoridades con fines organizativos y clasificatorios, es decir la confección de listados de miembros de batallones, de "inservibles o inútiles" y/o de gente que ya ha sido vacunada. De modo que por fuera de estas situaciones, la asignación con nombres resulta una rareza.

62 A su vez, dicha clasificación de los deportados a Martín García forma parte de la preocupación de los propios funcionarios de Buenos Aires y de los militares que residen en la isla. En diversas órdenes se establece que los indios requeridos para ser distribuidos serán seleccionados por determinado oficial: “Pondrá usted a disposición del Capitán Don Benito Cervín del Batallón de Artillería de Plaza, el número de indios que el indicará a usted, de los que se hayan allí en depósito para ser conducidos al ejército" (Documento 18). O directamente se aclara que debe trasladarse cierta cantidad de indígenas con especial cuidado de separar a quienes no sirven para el trabajo:

Por orden del Sr. Ministro de Marina se envía en el vapor Resguardo al capitán Don Bernardino Prieto para que conduzca a este puerto a todos los indios que trajo dicho vapor del Chaco, dejando allí únicamente las indias inservibles ya por su vejez como por cualquier defecto que las imposibilita para el trabajo, clasificando tanto de las indias como de los indios el nombre y edad aproximada de cada uno.

Espero que usted se dispondrá disponer lo necesario para que el capitán Prieto pueda llevar su cometido. (Documento 19)

Desde una errónea concepción, suele asociarse al concepto de genocidio con la cantidad de seres humanos asesinados, lo que para este caso en particular hace irrumpir la pregunta de cuántos indígenas estuvieron concentrados en Martín García. Al respecto, cabe aclarar que no abundan los papeles del AGA que den cuenta del número de personas incluidas en la lógica concentracionaria y distributiva de los prisioneros, sin embargo dichas prácticas se encuadran en el artículo 2 de la Convención para la Sanción y Prevención del Delito de Genocidio (1948):

se entiende por genocidio cualquiera de los actos mencionados a continuación, perpetrados con la intención de destruir, total o parcialmente, a un grupo nacional, étnico, racial o religioso como tal: d) Medidas destinadas a impedir nacimientos en el seno del grupo; e) Traslado por la fuerza de niños del grupo a otro grupo.

Las fuentes aquí trabajadas demuestran la existencia de un tráfico asiduo y una importante circulación de indígenas entre el puerto de Buenos Aires y Martín García.

Algunas directivas fijan con precisión el procedimiento a seguir, y con ello, permiten develar el afán de optimización y aprovechamiento de los recursos y la magnitud de los contingentes que iban de un lado a otro. Así, podemos encontrar fuentes que describen la remisión de indígenas en determinada embarcación, exigen la inmediata remisión a la ciudad de mujeres y chusma por igual medio, y en el acuse de recibo detallan el número de individuos que ingresan a la isla y la cantidad de los que se embarca hacia Buenos Aires:

Sirva usted disponer se reciban en depósito en esa isla, los indios y chusma que conduce el vapor "Santa Rosa" a cargo del Teniente Coronel Herrera y Ayudante Mayor Denis. 
En el mismo vapor remitirá usted todas las indias mujeres y chusma de los que anteriormente se mandaron a su parte, que se encuentran en condiciones de venir a esta Ciudad.

Acúsese recibo [ilegible], haberse recibido del Comandante Herrera y Ayudante Denis 98 indios - 120 chinas y 131 de chusma, y que se remiten a la Capital 63 chinas y 35 criaturas de las que se encontraban en depósito" (Documento 20)

Por otra parte, si bien la entrega a particulares y a funcionarios está fehacientemente documentada, al tratarse de fuentes de origen castrense, predomina el material ligado a los traslados e incorporación de los sometidos a las filas del ejército y la marina. En algunos de ellos nuevamente pueden leerse órdenes en las cuales se precisa que los oficiales a cargo seleccionarán a los futuros enrolados, la parcialidad de origen, el lugar de detención en la isla y el destino dispuesto: "Sírvase usted disponer que de los indios Ranqueles que existen en depósito sean entregados diez indios al Coronel Martín Guerrico, con destino a la Armada Nacional, los cuales serán a elección de este jefe" (Documento 21)

67 También en esa línea se establecía la remisión de indígenas hacia Martín García en determinada embarcación y se solicitaba el envío de indígenas que se incorporarían a distintas divisiones del ejército. Se destaca en dicha misiva la aclaración de que los mismos debían tomarse entre los que se encontraban en depósito y habían sido vacunados:

En el lanchón "Don Gonzalo" que va a esa isla conduciendo indios y otros destinados, deberá remitir a su regreso con la misma escolta que llevan aquellos, veinte indios vacuna-dos de los que anteriormente se le mandaron en depósito, para ser destinados diez al Regimiento de Artillería e igual número al Batallón de línea" (Documento 22)

Esta condición sanitaria formaba parte de las directivas estatales con los indígenas, sobre todo durante 1879, cuando una epidemia de viruela diezmó a los detenidos en la isla (Copello 1944: 106; Kröpfl 2003). Estas enfermedades eran consideradas un problema importante, pues lo que se buscaba era que los indígenas gozaran de un aceptable estado de salud para su posterior utilidad (Papazian y Nagy 2010, p. 8).

Sin poder determinar con precisión la cantidad de indígenas que fueron deportados a la isla Martín García, y desde allí distribuidos como fuerza de trabajo esclava a distintos lugares del territorio argentino, de todos modos el material del AGA permite tener una perspectiva de los aspectos cualitativos acerca de las políticas seguidas con los sometidos en las campañas militares. Además, por más que el número exacto resulte un enigma, la documentación evidencia un tráfico de indígenas muy fluido como parte de un plan de reparto de prisioneros en funcionamiento, por lo menos, durante más de una década.

\section{Conclusiones}

70 Consideramos que los debates teóricos referidos a la pertinencia o no de la utilización de términos como genocidio y campos de concentración, en el contexto histórico de la expansión militar del Estado sobre las parcialidades indígenas hacia fines del siglo XIX es de interés central para repensar las políticas llevadas adelante en Argentina con respecto a la población originaria. Desde esa perspectiva, el corpus documental del AGA (en concurrencia con otros archivos documentales como los del Arzobispado de Buenos Aires, la Congregación de los Hermanos de la Misión, etc) nos permite analizar y entender la función de Martín García durante el período de expansión estatal. Estudiar y reponer 
diferentes documentos sobre los modos de circulación de indígenas dentro de diferentes instituciones disciplinarias en la isla ha sido el principal objetivo de este trabajo.

Dicho análisis nos permite recrear sentidos sobre la práctica cotidiana en un campo de concentración particular durante un genocidio a escala nacional. En otras palabras, buscamos dar con un lugar (la isla Martín García) donde la documentación oficial de la Armada Argentina nos permita revelar la práctica de concentración y disciplinamiento indígena. Hemos focalizado nuestro recorte en las formas de control, explotación y distribución, observando diferentes agencias que intervienen y acceden a los "cuerpos disponibles"; desde la Armada y el Ejército hasta trabajos cotidianos dentro de la isla. Incluimos también aquellos documentos referidos a las formas de "domesticar" los cuerpos por medio del accionar de las agencias sanitarias de la Armada; quienes informan, actúan y prescriben acciones concretas para "normalizar" al salvaje.

Sin embargo Martín García no es un espacio inconexo o aislado del resto del territorio argentino, será entonces la isla un campo abierto a entradas y salidas de indígenas que remitidos a este punto son concentrados y disciplinados para luego subjetivarlos como cuerpos disponibles al servicio de otras agencias.

Cada una de las órdenes que disponían de los vencidos en las campañas militares, para ser entregados a un patrón, a una familia "acomodada" o a un superior en las Fuerzas Armadas, representa una pieza de un rompecabezas que en su conjunto compone un plan sistemático de reparto de prisioneros, vigente, por lo menos, durante una década y media. En principio tal vez de modo irregular y esporádico, aunque devenido masivo en el contexto de la Conquista del Desierto y la enorme cantidad de contingentes que quedaban a disposición del estado nacional.

Si bien las transcripciones permiten agrupar los destinos en tres categorías, el servicio doméstico, las actividades productivas y las Fuerzas Armadas, resulta inabarcable sistematizar los diferentes lugares hacia donde los indígenas fueron entregados. En algunos casos, como el Batallón de Artillería de Plaza, las órdenes indican una y otra vez la designación hacia un punto, sin embargo en otros, sólo existe una única mención, generando un serio interrogante acerca de los silencios y las posibles trayectorias que aún permanecen en las sombras.

Este tipo de registros permiten un análisis de diferente escala. Por un lado, cuando se consignan los nombres de personas o parcialidades, aportan a la reconstrucción de historias de vida de las víctimas, de trayectorias individuales, familiares y/o comunitarias; dan cuenta de aquellas autoridades involucradas en la distribución; y permiten situar y ubicar los posibles destinos de los indígenas sometidos. Por otro, desde un enfoque más amplio brinda la posibilidad de caracterizar y describir con claridad y precisión una política concentracionaria y de distribución de prisioneros poco conocida y difundida. A diferencia de la literatura del desierto (Guglielmino 1976, p. 7) y las corrientes hegemónicas dentro de la historiografía académica, que han puesto el énfasis sobre las campañas militares como elemento central en el proceso de organización nacional, la documentación del AGA permite iluminar aspectos que funcionan como no-relatos y noeventos dentro de las narrativas nacionalistas (Trouillot 1995; Delrio 2005).

76 En otros términos, el material presenta un importante desafío a la tradicional explicación evolutiva que aborda con detalle la modernización de la Argentina con la Conquista del Desierto, la incorporación de tierras, la organización del territorio, la construcción de 
ferrocarriles y el arribo de la inmigración, y a la vez obtura el análisis de las políticas aplicada con los indígenas y sus trayectorias posteriores.

77 En suma, las fuentes aportan a trazar los recorridos y las trayectorias impuestas a los derrotados, y su utilización como mano de obra disponible, a desentrañar ciertas prácticas estatales genocidas que han permanecido silenciadas, y a dar cuenta de una serie de políticas de sometimiento, deportación, confinamiento y distribución, que paradójicamente estuvieron enmarcadas en un proceso histórico naturalizado y percibido como parte del avance de la civilización.

Será tarea pendiente dar cuenta de un sinfín de historias condensadas en la isla. Historias que entrelazan procesos de resistencias y fugas de indígenas en la isla; historias que marcan itinerarios forzados en los repartos de familias; las historias de los que han perdido el nombre tras los bautismos impuestos; historias que sitúan a la isla en un presente, producto de las memorias que los antiguos han legado a las actuales generaciones.

Presidiario

Indios.

Asistentes

(Fin primer carilla)

En el Horno

En el Cementerio.

En el Potrero.

En la quinta de la Comandancia.

(Fin $2^{\circ}$ Carilla)

Carpintería

Herrero

Hospital [ilegible]

Proveduria

Resumén

12 Presidiarios.

22 Asistentes

5 en el horno.

2 en el Cementerio

5 en el Potrero y

1 en la Quinta

1 Carpinteria

1 Herrero

2 empleados en el hospital

1 " en la proveduria. 
Buenos Aires, diciembre 19/1878

Al Señor Jefe de la isla de Martín García Coronel Don Donato Álvarez:

En el lanchón "Don Gonzalo" que va a esa isla conduciendo indios y otros destinados, deberá remitir a su regreso con la misma escolta que llevan aquellos, veinte indios vacunados de los que anteriormente se le mandaron en depósito, para ser destinados diez al Regimiento de Artillería e igual número al Batallón de línea.

Dios guíe a usted.

Firma: Luís M. Campos

\section{BIBLIOGRAPHY}

Agamben, G. (1998). Homo sacer. El poder soberano y la nuda vida. Valencia: Editorial Pre-Textos. Agamben, G. (2004). Estado de excepción. Homo sacer II, I. Buenos Aires: Adriana Hidalgo editora. Añon Suarez M., Pepe F. y Harrison P. (2009, junio 11-14). Descosificación de las colecciones de Antropología Biológica en el Museo de la Facultad de Ciencias Naturales de la U.N.L.P. En Latin American Studies Association Congress, Work Group, Hacia una reparación del despojo colonial y neocolonial: la restitución de restos humanos, material asociado, y tierras indígenas en la Argentina. Rio de Janeiro.

Bayer, O. (Coord.) (2010). Historia de la crueldad argentina. Julio A. Roca y el genocidio de los pueblos originarios. Bue-nos Aires: Ediciones El Tugurio.

Briones, C. y Delrio, W. (2002). Patria sí, Colonias también. Estrategias diferenciales de radicación de indígenas en Pampa y Patagonia (1885-1900). En: A. Teruel, M. Lacarrieu y O. Jerez (Comps.) Fronteras, Ciudades y Estados (pp. 45-78) Córdoba: Alción Editora.

Carrasco, M. (2000). Los derechos de los pueblos indígenas en Argentina, Buenos Aires: IWGIA, Vinciguerra.

Charny, I. (1999). Classification of genocide in multiple categories. En I. Charny (Editor), Enciclopedya of Genocide (pp. 3-9). California: ABC-CLIO.

Copello, S. L. (1944). Gestiones del Arzobispo Aneiros en favor de los indios hasta la conquista del desierto. Buenos Aires: Editorial Difusión.

De Jong, I. (2005, noviembre 22-25). Identidades mestizadas, identidades escindidas: El proceso de etnogénesis entre los indios amigos de la frontera bonaerense (1860-1880). En VI Congreso Internacional de Etnohistoria, Ciudad de Buenos Aires.

De Jong, I. (2007). Políticas indígenas y estatales en Pampa y Patagonia (1850-1880). Habitus, 5 (2), Jul/dic., 301-331.

Delrio, W. (2005). Memorias de expropiación. Sometimiento e incorporación indígena en la Patagonia 1872-1943. Bernal: Editorial de la Universidad Nacional de Quilmes. 
Delrio, W. y Escolar, D. (2009, octubre 28-31). Trayectorias y memorias de la diáspora forzosa de prisioneros indígenas entre Patagonia y Cuyo, S. XIX - XX, XII Jornadas Interescuelas/Departamento de Historia. San Carlos de Bariloche.

Delrio, W., Lenton, D., Musante, M., Nagy, M., Papazian, A. y Pérez, P. (2010). Discussing the Indigenous Genocide in Argentina: Past, Present and Consequences of Argentinean State Policies toward Native Peoples. Genocide Studies and Prevention, University of Toronto Press, 5 (2), August, 139-159.

Fitte, E. (1971). Martín García. Buenos Aires: Ediciones Emecé.

Feierstein, D. (2007). El Genocidio como práctica social. Entre el nazismo y la experiencia argentina. Buenos Aires: Fondo de Cultura Económica.

Foucault, M. (1976). Vigilar y castigar. México: Siglo XXI Editores.

Foucault, M. (1987). Historia de la sexualidad, Vol. I.- La voluntad de poder. México: Siglo XXI Editores.

Hardt, M. y Negri, T. (2000). Imperio. Cambridge, Massachussets: Harvard University Press.

Hux, M. (2003) [1991]. Caciques Pampas y Ranqueles. Bue-nos Aires: Editorial Elefante Blanco.

Hux, M. (2003) [1991]. Caciques Pehuenches. Buenos Aires: El Elefante Blanco.

Hux M. (2003) [1991]. Caciques Puelches, Pampas y Serra-nos. Buenos Aires: El Elefante Blanco.

Kröpfl, P. (2003). Misteriosa Martín García. La cenicienta del Plata. Buenos Aires: Dunken.

Lenton, D. (2010). La "cuestión de los indios" y el genocidio en los tiempos de Roca: sus repercusiones en la prensa y la política. En O. Bayer (coord.), Historia de la crueldad argentina. Julio A. Roca y el genocidio de los pueblos originarios (pp. 29-49). Buenos Aires: Ediciones El Tugurio.

Lenton, D. (2007, julio 18-21). Genocidio y políticas indigenistas en Argentina: aportes para un debate. En II Congreso de las Lenguas, Universidad Nacional de Rosario y SERPAJ, Buenos Aires.

Lenton, D. (2005). De centauros a protegidos. La construcción del sujeto de la política indigenista argentina desde los debates parlamentarios (1880 - 1970). Tesis Doctoral. Universidad de Buenos Aires, Facultad de Filosofía y Letras, Argentina.

Lenton D. y Sosa, J. (2009, noviembre 26-29). La expatriación de los pampas y su incorporación forzada en la sociedad tucumana de finales del siglo XIX, Jornadas de Estudios Indígenas y Coloniales, C.E.I.C. Jujuy.

Mases, E. H. (2002). Estado y cuestión indígena. El destino final de los indios sometidos en el sur del territorio (1878-1910). Buenos Aires: Prometeo Libros/Entrepasados.

Mases, E. H. (2010). La construcción interesada de la memoria histórica: el mito de la nación blanca y la in-visibilidad de los pueblos originarios. Revista Pilquen, año 12, № 12. CURZA, Universidad Nacional del Comahue. Viedma.

Musante, M. (2009, octubre 28-31). La construcción del territorio chaqueño como parte de un proceso genocida y sus implicancias actuales en las demandas de los pueblos originarios, XII Jornadas Interescuelas-Departamentos de Historia. Universidad Nacional del Comahue. Facultad de Humanidades. Centro Regional Universitario Bariloche.

Nagy, M. (2010, septiembre 20-22). Itinerarios del sometimiento indígena. De la frontera bonaerense a la isla Martín García, IV Jornadas de Historia de la Patagonia. Santa Rosa. La Pampa.

Nagy, M. y Papazian, A. (2009, octubre 28-31). De la Isla como Campo. Prácticas de disciplinamiento indígena en la Isla Martín García hacia fines s. XIX, XII Jornadas Interescuelas- 
Departamentos de Historia. Universidad Nacional del Comahue. Facultad de Humanidades. Centro Regional Universitario Bariloche. 28 al 31 de Octubre.

Papazian, A. y Nagy, M. (2010). Prácticas de disciplina-miento indígena en la isla Martín García hacia fines del siglo XIX, Revista TEFROS, 8 (1 y 2), Diciembre. Río Cuarto, Córdoba.

Papazian, A. (2010, septiembre 20-22). “Itinerarios “blancos”. Agencia militar y eclesiástica en la isla Martín García (1870-1880), 4ª Jornadas de Historia de la Patagonia. Santa Rosa. La Pampa.

Pérez P. (2007, noviembre 20-22). Represión y resistencia: una aproximación a los campos de concentración en el territorio patagónico a fines del siglo XIX, II Encuentro Internacional Análisis de las Prácticas Sociales Genocidas. Universidad Tres de Febrero, Buenos Aires.

RIG. Red de Investigadores sobre Genocidio y Política Indígena en Argentina. DÍAZ, Sergio, Lenton, Diana, Papazian, Alexis, Pérez, Pilar, Delrio, Walter y Nagy, Mariano (2007). Aportes para una reflexión sobre el genocidio y sus efectos en relación a la política indígena en Argentina. ISociología, Revista Electrónica de Ciencias Sociales. [En línea] <http://a-r-w- e-b.com.ar/ isociologia> Sosa, N. (2001). Mujeres indígenas en la Pampa y la Patagonia. Buenos Aires: Editorial Emecé.

Trinchero, H. H. (2005). Estigmas del genocidio indígena en el cuerpo del Estado-nación, Revista Espacios, 32, junio-julio, 33-38.

Trouillot, M. R. (1995). Silencing the Past. Power and the Production of History. Boston: Beacon Press.

Valko, M. (2010). Pedagogía de la Desmemoria. Crónicas y estrategias del genocidio invisible. Buenos Aires: Ediciones Madres de Plaza de Mayo.

\title{
APPENDIXES
}

\section{ANEXO 1. TRANSCRIPCIÓN DE DOCUMENTOS DEL ARCHIVO GENERAL DE LA ARMADA (AGA). Tópico: Registros sobre la explotación laboral y el disciplinamiento}

\author{
DOCUMENTO 1 -AGA - Caja 15273 \\ INSPECCION Y COMANDANCIA \\ GENERAL DE ARMAS \\ DE LA REPUBLICA ARGENTINA
}

Buenos Aires Enero 25/876.

Al Gefe Superior de la Isla de Martín García, Coronel Dn. Julio Campos.

Por el vapor "Buenos Aires" se remiten cincuenta y dos Indios y cinco familias, cuya lista se acompaña, que han sido destinados á los trabajos de esa Isla hasta nueva disposición. Lo que se comunica a V.S. para su conocimiento y efecto consiguiente.

Dios Gue. A V.S.

Luis María Campos. 
[Fin carilla 1]

Lista nominal de los Indios y familias en depósito en el Batallón $3^{\circ}$ de Línea.

\begin{tabular}{|c|c|c|c|c|c|}
\hline 1. & Cirilo Manquillan & 28. & Mariano & & \\
\hline 2. & Antonio Perez & 29. & Alejo Lacoste & 1. & Juana \\
\hline 3. & Manquelao & 30. & Martín Perez & 2. & Yuviliana \\
\hline 4. & Juan Libertino & 31. & Manuel Gonzalez & 3. & Marcela \\
\hline 5. & Coloqueo & 32. & Fermin Juan & 4. & Micaela \\
\hline 6. & José Ramón & 33. & Hallgy & 5. & Seferina \\
\hline 7. & José Martín & 34. & Tiburcio & & \\
\hline 8. & Marcelino & 35. & Clemente Lopez & & \\
\hline 9. & Pascual Gonzalez & 36. & Manuel Lopez & & \\
\hline 10. & Mariano José & 37. & Iarpasolo? & & \\
\hline 11. & Seferino Pérez & 38. & Ignacio Lopez & & \\
\hline 12. & Domingo & 39. & Arriola Videla & & \\
\hline 13. & Antonio & 40. & Saturnino Lopez & & \\
\hline 14. & Jacinto Villa & 41. & José Lopes & & \\
\hline 15. & Juan & 42. & Lauriano Lopez & & \\
\hline 16. & Santiago & 43. & Luciano Lopez & & \\
\hline 17. & Juan Lopez & 44. & Mariano Avedoia & & \\
\hline 18. & Marcelino Ortiz & 45. & Santiago Lopez & & \\
\hline 19. & Juan Videla & 46. & Ruliain? & & \\
\hline 20. & Seferino López & 47. & José & & \\
\hline 21. & Julián Ragunilo & 48. & José Romero & & \\
\hline 22. & Vicente Mecluma? & 49. & Morel & & \\
\hline 23. & Juan Dionicio & 50. & José Alvarez & & \\
\hline 24. & Pedro Mathis & 51. & Luciano Ponce & & \\
\hline
\end{tabular}




\begin{tabular}{|l|l|l|l|l|}
\hline 25. & Juancito Roman & 52. & Celestino Vidal & $\begin{array}{l}\text { Bs As Enero 25/76 } \\
\text { Firma: José N. Romero } \\
\text { Firma: Luis María } \\
\text { Campos }\end{array}$ \\
\hline 26. & Luciano Magoya & & & \\
\hline 27. & José Julián & & & \\
\hline
\end{tabular}

DOCUMENTO 2 - AGA - Caja 15273

INSPECCION Y COMANDANCIA

GENERAL DE ARMAS

DE LA REPUBLICA ARGENTINA

Al Sr.Cmdte. Militar de Martín García, Coronel Dn. Julio Campos

En contenstación a la nota de U.S. de fha. 21 del corriente y a fin de que pueda llenarse la ... de ordenanza

Art. 8 Fes. 8 - Trab $3^{\circ}$ y cuyo reglam. hiso el Sr. Com. De Guerra, se dice a U. S., que siendo indios que algunos ni tienen nombre se acepta el medio que indica de darles uno haciéndoles comprender deben tenerlo presente pues que el les debe servir para justificar la revista y apercibir sus haberes.

Dios Gue. A V.S.

Firma: Luis María Campos.

DOCUMENTO 3 - AGA- Caja 15278

Martín García. Nbre. 2/878.

Al Sr. Gefe del punto, Cnel Donato Álvarez.

Tengo el honor de acompañar a Vs una relación de los individuos del Cuerpo de mi mando que son inútiles para el servicio activo, unos por impedimento físico y otros por avanzada edad.-

Esperando que VS, si lo tiene a bien y previo reconocimiento Médico se sirva elevando al conocimietno de la Superioridad para la resolución que estime por conveniente.- Dios Gue a VS.= Benjamin Cárcova.

Martín García Nbre. 2/878.

Informe del Cirujano de la Guarnición - Álvarez - Sr. Coronel:

En virtud de la orden que antecede he practicado el re-conocimiento médico de cada uno de los individuos del Bat. Art. de Plaza cuya relación se acompaña e informe como sigue: Cabo Gabriel Tello -55 años- padece de vicios orgánicos al corazón; esfuerza a disminuir la vista, espuesto a morir súbitamente: Suficientes causas para escepción del servicio de las armas.

Soldado Manuel Sosa - Fue remitido a Buenos Aires con certificado de demencia. 
Jacinto Molina - Indio de 40 años, reumatismo articular crónico, rengo, enfermizo y deteriorado.

[fin primera carilla]

Soldado Manuel Cunial- indio, ciego. Se pidió su baja hace un mes cin su informe correspondiente.

Id. Juan Felipe - Indio, 40 años, padece de una fractura antigua de la mano dcha, temperamento linfático, abdomen muy pronunciado, sobredimensión [ilegible]; movimientos fatigosos y difíciles. Carece de la talla militar requerida, para su vestido se necesita una medida suya, especial, propia.

Id. Manuel Godoy. Indio- 80 años mas o menos. Ha empezado a perder la vista, de noche no ve uno a muy corta distancia-

Id. Martín Callfumai- indio- es joven. Este pedido encaja con el informe correspondiente por fractura del cuello del fémur.

Id. José Peneño. Indio- de 35 años. Por una fractura antigua en el tercio superior de la tibia derecha, no puede hacer muchas ayudas - no puede andar lijero y al correr se cae sin poderlo evitar.

Saturnino López. Indio. 28 años. Una fractura mal cicatrizada en el tercio inferior de la tibia le quita la fuerza del miembro y cae sin poderse sostener al ejercitar una marcha [ilegible]

José Eugenio. Indio - 45 años - dos dedos de la mano izquierda sin movimientos de estension - una fractura esterna cortal- constituciones

[fin segunda carilla]

arruinada hasta el marasmo- tiene ceguera? incipiente.

Pacheco Flores -indio- 55 años. Reumatismo articular crónico. Constituciones arruinadas, marasmo [ilegible] nasal - hernia desecha avanzada.

Antonio Mastrif -indio- -50 años- constituciones aniquiladas, raquíticas.

Manuel Rojas -indio- 70 años - mas o menos- antigua fractura de la tibia derecha.

Antonio Meliton -45 años- rengo -fracturas antiguas del hombro y rodillas esquivas ...

[poco claro]

Santiago Pérez -indio- 35 años- tiene fractura antigua del hombro izquierdo - le impide el manejo del fusil.

Pancho Rosas -50 años- constituciones arruinadas, enfermisas, marasmática moralmente yace ya en la inutilidad.

Por la relación que prima se puede señalar que los soldados mencionado no podrán seguir prestando el buen servicio que se requiere en su puesto; y el Gefe del Batn. ha adquirido sus duda la prueba práctica de esto, cuando solicito la baja de estos individuos [ilegible] e incurables, que no podrán mejorar su estado de situación por mas que se haga.

El médico juzga que el mejor destino de estos individuos podrá ser un buen [ilegible] con la atención y el mejor que se seguire. Si bien podrán alguno de ellos prestar servicios mecánicos en el Cuartel. 
En cuanto tengo que informar con cumplimiento de lo dispuesto por V.S

Martín García, Nbre. $1^{\circ}$ de 1878 - Sabino O'Donell

Clases nombre

Cabo $1^{\circ}$ Gabriel Tello

Soldado Manuel Sosa

Jacinto Molina

Mariano Cunial

Juan Felipe

Manuel Godoy

Martín Callfumai

José Peneño

Antonio López

Pacheco Flores

Antonio Martínez

Manuel Rojas

Antonio Meliton

Santiago Pérez

Pancho Rosas-

Martín García. Nbre. 1/878.

Firma: Benjamín Carcova-

DOCUMENTO 4 - AGA- Caja 15280

Cirujano de la Guarnición

Martín García. Mzo. 3 de 1879.

Al Sr. Comandante Militar de la Isla, Cornl. D. Maximino Matoso.

Siendo necesario continuar con la vacunación de los indígenas, y habiéndome concluido el virus vacinico humano, ruego á V.S se sirva pedir a quien corresponda lo que solicito por ser muy necesario en cantidad suficiente pa vacunar como cien o más personas.

Dios guarde á V.S

Firma: Sabino O'Donnell

DOCUMENTO 5 - AGA- Caja 15278

El Médico de la Guarnición.

Martín García, Dic. 10 de 1878.

Al Sr. Gefe de la Guarnición Coronel Dn. Maximino Matoso. 
Cumpliendo lo dispuesto por V.S., en 30 del mes p.p. empecé a vacunar a los Indios recién llegados, desde el $1^{\circ} \mathrm{hta}$. El 3 , en que concluí de vacunar a todos los indios del depósito habiendo emprendido por orden verbal de V.S..

Hasta hoy no se notan visiblemente los resultados de la vacunación pero aún podrán manifestarse más tarde.

Entre los 148 Indios que llegaron últimamente había uno que traía frescas las cicatrices de la viruela, de la que había sido acometido 15 o 20 días según la relación y de algunos de sus compañeros. Dos o tres indios mas acusaban dolores de cabeza y de espaldas y se les notaba la fiebre que precede a la erupción.

Indudablemente venían ya impregnados o contagiados.

Al vacunarlos se ha desarrollado la epidemia entre ellos, llegando hoy el número de virulentos a once, de los que fallecieron dos hoy temprano. Se creía que la vacunación hubiera influido en la propagación

(fin carilla 1)

y aumento de los enfermos, pero semejante opinión solo la ignorancia puede abrigar. Jamás el preservativo, el antídoto, puede producir el mal o envenenamiento del que es antagonista.

La absorción del virus vacinico humano jamás podrá producir la erupción de viruela, la que (ilegible) con un principio, con virus, o como quiera llamarse que circula en la sangre y que en presencia de un antagonista desaparece, se pierde, se anula.

Es llegado el momento de contestar una de las consultas que se me ha escrito V.S dirigiendomé respecto al travajo de estos Indios, y á los males que pueda causarles.

El travajo pesado y laborioso no podrá menos que ser nocivo a muchos de ellos. El indio es flojo y acostumbrado al ocio. Todo esfuerzo es para él estraordinariamente penoso y en la estación en que estamos, en la debilidad en que se hallan los más, por su falta de buena alimentación, en las penurias que viven padeciendo; el abatimiento moral, pues sienten ellos la pérdida del desierto como puede sentir un Rey la de sus palacio; y además, la enfermedad que va tomando crecer, todo esto aconseja la mayor moderación en el trabajo.

Pero es preciso al huir de (fin segunda carilla ) un estremo, no caer en otro, tanto o más peligroso q el ecceso de travajo.

No conviene que estos hombres estén encerrados, aglomerados, y sin movimiento, en esa actitud ó manera de ser ellos, q pasan 24 horas y aún más, tirados en su mala causa.

Es preciso sacarlos al aire libre y aún obligarlos a hacer un poco de ejercicio.

Sacarlos temprano a trabajar, sin apurarlos mucho, y hacerlos retirar cuando el sol molesta ya creo que será un medio de atender a su salud.

Estos indios están también acostumbrados al baño, y sin eso, creo q será conveniente que a la hora de retirarlos ( 9 o 10 de la mañana) se les haga bañar, o bien por las tardes, llevándolos a las tres al Río.

No me atreveré a indicar a V.S otras medidas de higiene de aseo en sus habitaciones, ropas y camas, corte de cabello q todos llevan crecidísimo y demás cuidados que son demasiado vulgares por q temeria hacer una ofensa. 
Dios gde. á V.S

Firma: S. O’Donnell.

\section{DOCUMENTO 6A - AGA- Caja 15274}

Piquete de Indios

Lista de los Indios qe tiene el espresado para el recibo de uniformes de verano en el día de la fecha

\begin{tabular}{|c|c|c|c|c|c|c|c|}
\hline A Saber & & Kepis & Blusas gris & camisas & calzoncillos & chiripaes & Sapatos \\
\hline Capitanejo & José Celao & 1 & 1 & 1 & 1 & 1 & 1 \\
\hline Indios & Juan Pio & 1 & 1 & 1 & 1 & 1 & 1 \\
\hline “ & Ambrosio Sotelo & 1 & 1 & 1 & 1 & 1 & 1 \\
\hline “ & Venancio Jose & 1 & 1 & 1 & 1 & 1 & 1 \\
\hline “ & Marcelino Crespo & 1 & 1 & 1 & 1 & 1 & 1 \\
\hline “ & Tomas Torres & 1 & 1 & 1 & 1 & 1 & 1 \\
\hline “ & N. José & 1 & 1 & 1 & 1 & 1 & 1 \\
\hline “ & Jose Pardo Maican & 1 & 1 & 1 & 1 & 1 & 1 \\
\hline “ & N. Cayupan & 1 & 1 & 1 & 1 & 1 & 1 \\
\hline “ & Julian Gutilan & 1 & 1 & 1 & 1 & 1 & 1 \\
\hline “ & Sabalia Quintulem & 1 & 1 & 1 & 1 & 1 & 1 \\
\hline “ & Santiago N. & 1 & 1 & 1 & 1 & 1 & 1 \\
\hline “ & Manuel Calfine & 1 & 1 & 1 & 1 & 1 & 1 \\
\hline
\end{tabular}

Martín García, Marzo 8/874

DOCUMENTO 6B - AGA- Caja 15280

Buenos Aires, Agosto 10 de 1880

Al Sr. $2^{\circ}$ Jefe de Martín García Coronel Don Maximino Matoso:

En contestación a su nota de fecha 7 del corriente pidiendo autorización para reemplazar con los indios presos las bajas ocurridas por diversas causas en el Piquete "Guarda Costa", de esa Guarnición, hasta reintegrarlo en su fuerza primitiva, se dice a usted, que: Constando el Piquete "Guarda Costa", de un sargento y veinte nueve soldados queda usted autorizado para dar el alta de la forma indicada doce indios de los que existen allí presos.

Dios guíe a usted.

Firma: Joaquín Viejobueno 
DOCUMENTO 7 - AGA- Caja 15283

Martín García Noviembre 30/83.

Al Señor Inspector y Comandante General de Armas, General de División Dn Joaquín Viejobueno.

Tengo el honor de poner nuevamente en conocimietno de V.S que el personal del Batallón de Artillería de Plaza es insuficiente para llevar debidamente el servicio de esta Plaza a mas que su composición es mala, pues sus dos terceras partes son indios sacados de entre los mis-mos que están con la denominación de presos y las guardias de los polvorines, de los galpones donde se alojan los indios y chinas y del Puerto Viejo son montadas sin oficiales, por la carencia de ellos, pues sólo hay presentes cinco en el Batallón, de estos, uno está encargado de la mayoría, otro desempeña las funciones de ayudante, y un tercero es habilitado de la guarnición, solo quedan dos para las [ilegible] (fin primer carilla)

las guardias están a cargo de clases indios, que son también los soldados en su mayor parte; siendo los cui-dadores y cuidados de la misma raza, una misma familia, se puede decir; los oficiales de la Plana Mayor de esta

Comandancia son pocos para el servicio de campo y de-más que hay que desempeñar diariamente; la Subprefectura de Marina no está en mejores condiciones para llenar su cometido pues solo tienen seis marineros, siendo de estos dos indios y en su totalidad poco tienen de marineros, sería el nombre subordinado o cual cosa con los oficiales subalternos, que son inapropiados marineros.

Con semejante personal, Señor Comandante General, no será extraño que se repitan casos como el que hou dí cuenta a V. S. por telegrama. Por las razones espuestas verá V. S. que es de urgente y suma necesidad mejorar y aumentar el personal de la Guarnición de esta Plaza dando altas cristianas y más oficiales, solo así, Señor Co-mandante (ilegible.)

Firma Leopoldo Nelson. Comandante del Batallón Artillería de Plaza

DOCUMENTO 8 - AGA- Caja 15281

Buenos Aires abril 11 de 1881

Al Sr. $2^{\circ}$ Jefe de Martín García Coronel Don Maximino Matoso:

Se remiten a esa isla con destino a los distintos trabajos de la misma a los indios José Manuel y Nicanor Gabriel, los mismos que deben figurar en los indios presos, cuyos indios los lleva el lanchón "Martín García”.

Dios guíe a usted.

Firma: Donato Álvarez

DOCUMENTO 9 - AGA- Caja 15282Silvia2014-09-24T19:49:00

Presidiarios e Indios que viven fuera del Lazareto.

1. Felipe Sierra

2. Florencio Martínez

3. María Medina

4. Joaquín González

5. Borja Moreno 
6. Jacinto Bilbao Asistente

7. José Ramírez

8. Manuel Maldonado

9. Maximiliano Bar

10. Ant $^{\circ}$ Siunta

11. Hilario Conde Asistente

12. Pedro Ramírez

1. Tomás Rosas

2. José Enrique

3. Maldonado

4. Juan N.

5. Juan Sosa

6. Ceferino López

7. José Giménez

8. Juan Zabala

9. Juan Sandoval

10. Pancho Rosas

11. (sin nombre)

12. Máximo

13. Luciano Migoya

14. Luciano López

15. Ceferino Artigo

1. Arriola Alvarez Asistente

2. Santos Pérez

3. Pacheco Nicolás

4. Alejo Acosta

5. José González

6. Pulquichea

7. Saturnino López

1. Jacinto Molina

2. Juan Centeno

3. Ignacio Arriola

4. Pancho Ignacio

5. Marcelino Calfunel

1. Manuel Martínez

2. Martín Salas.

1. Blas Román

2. Carranza

3. Santiago Pérez

4. Caciola 3 caballeriza

5. Zúniga

1. Miguel Segunare.

1. Martín Servian

1. Pamllante

1. Bernabé Arno

2. Pedro Marquez

1. Manuel Guenpuí.

52 Total 
(Sin firma, ni fecha. Se infiere es de 1882 por el nombre de los indígenas que se repite en otros docs. para esa fecha.).

\section{DOCUMENTO 10 - AGA- Caja 15280}

El Comandante del "Bergantín Rosales"

Martín García Agosto 2/879.

Al Señor Gefe de esta Fortaleza. Coronel Don Donato Álvarez

Me dirijo a V.S. para darle cuenta que según su orden dejo en calidad de depósito en esta 6 (indios) de los mas inútiles, habiendo recibido sus raciones por 15 días debiendo suministrar la carne el Proveedor de esta Plaza.

Dios Guuarde a V.S.

Firma: Lázaro Iturrieta. Súmese recibo fcha.. archivesé.

Firma: Donato Álvarez.

DOCUMENTO 11 - AGA- Caja 15279

Buenos Aires, febrero 19 de 1879

Al Sr. Jefe Superior de la isla de Martín García Coronel Don Donato Álvarez:

Sirva usted disponer se reciban en depósito en esa isla, los indios y chusma que conduce el vapor "Santa Rosa" a cargo del Teniente Coronel Herrera y Ayudante Mayor Denis.

En el mismo vapor remitirá usted todas las indias mujeres y chusma de los que anteriormente se mandaron a su parte, que se encuentran en condiciones de venir a esta ciudad.

Dios guíe a usted.

Luís María Campos Martín García, Febrero 20 de 1879

Acúsese recibo [...], haberse recibido del Comandante Herrera y Ayudante Denis 98 indios - 120 chinas y 131 de chusma, y que se remiten a la Capital 63 chinas y 35 criaturas de las que se encontraban en depósito.

Firma: Matoso

\section{ANEXO 2. TRANSCRIPCIÓN DE DOCUMENTOS DEL ARCHIVO GENERAL DE LA ARMADA (AGA) Tópico: Registros en torno a la práctica de repartimiento de indígenas}

\section{DOCUMENTO 12 -AGA- CAJA 15279}

Buenos Aires, Marzo 27 de 1879 Al Jefe Superior de la isla de Martín García:

Sírvase usted disponer le sea entregado al portador de la presente al indio Jacinto Segundo Puelpan que existe en depósito en esa isla.

Dios guíe a usted.

Firma Luís María Campos 


\section{DOCUMENTO 13 -AGA- CAJA 15272}

Buenos Aires, Septiembre 11 de 1872

Al Sr. Comandante Militar de Martín García Coronel Don Luis Py.

Se ha recibido en esta Comandancia General la nota de usted fecha 9 del corriente, en la que dice que con el Teniente Don Antonio Paganini remite al Cuartel del Retiro de esta ciudad, los once indios que se le ordenó en nota 4 del corriente remitiera a ésta.

En contestación a usted se dice a usted que han sido recibidos los indios de que se trata.

Dios guíe a usted.

Firma: Benjamín Victorica

\section{DOCUMENTO 14 -AGA- CAJA 15287}

Buenos Aires, Febrero 4 de 1886 Al Sr. Comandante Militar de la isla de Martín García:

Comunico a usted que por resolución superior de fecha del $1^{\circ}$ del corriente mes, se ha resuelto sean entre-gados al Sr. Gobernador del Territorio de Misiones Coronel Don Rudecindo Roca los indios con sus familias que se encuentran en la isla de Martín García y que han revistado hasta ahora en calidad de indios presos.

Al propio tiempo se comunica que ha sido encargado para recibir de ellos el Capitán Don Justo Domínguez del Batallón $1^{\circ}$ del Regimiento de mando del Señor Gobernador del Territorio de Misiones.

Dios guarde a usted

Firma: M. Cordero

\section{DOCUMENTO 15-AGA- CAJA 15279}

Buenos Aires, Marzo 12 de 1879

Al Señor Jefe de la isla de Martín García Coronel Don Donato Álvarez:

Sírvase usted disponer sean entregados al Señor Don Gregorio Torres, o a su orden, once indios de los existentes en esa isla, con sus mujeres respectivas e hijos.

Dios guíe a usted

Firma Luís María Campos

[Sobre el margen izquierdo de la orden]: En marzo 13 se entregaron al apoderado del Dr. Torres 4 indios, 4 chusmas y 7 criaturas.

\section{DOCUMENTO 16 -AGA- CAJA 15279}

Buenos Aires, abril 7 de 1879 Al Jefe superior de la isla de Martín García:

Sirva usted disponer le sean entregados al portador de la presente diez familias indígenas compuesta del indio, china e hijos debiendo la que no tenga marido ponerlo de los que revisten en la isla, mayores de 40 años, los cuales son ocho para Don Gregorio Torres y dos para Don Carlos Casares.

Dios guíe a usted

Firma: [Ilegible]

DOCUMENTO 17 -AGA- CAJA 15285 
Buenos Aires, Noviembre 21 de1884 Al jefe militar de la isla de Martín García:

Con esta fecha se ha dispuesto que usted proceda a remitir a la mayor brevedad, con destino a los talleres de Marina del Tigre, a los indios Benito, Piní y Bartolo y su mujer Juanita con una chiquita de año y medio, que existen entre los que se encuentran al servicio de esa isla, debiendo dar usted inmediato cumplimiento a esta orden.

Dios guarde a usted.

Firma: Joaquín Viejobueno

DOCUMENTO 18 -AGA- CAJA 15280

Campamento en la Chacarita, junio 19 de 1880

Pondrá usted a disposición del Capitán Don Benito Cervín del Batallón de Artillería de Plaza, el número de indios que el indicará a usted, de los que se hayan allí en depósito para ser conducidos al ejército.

Dios guíe a usted.

[Firma ilegible]. Matoso acusa recibo en junio 23

DOCUMENTO 19-AGA- CAJA 15280

Buenos Aires, noviembre 12 de 1879

Al Sr. Jefe de la isla de Martín García Coronel Don Donato Álvarez:

Por orden del Sr. Ministro de Marina se envía en el vapor Resguardo al capitán Don Bernardino Prieto para que conduzca a este puerto a todos los indios que trajo dicho vapor del Chaco, dejando allí únicamente las indias inservibles ya por su vejez como por cualquier defecto que las imposibilita para el trabajo, clasificando tanto de las indias como de los indios el nombre y edad aproximada de cada uno.

Espero que usted se dispondrá disponer lo necesario para que el capitán Prieto pueda llevar su cometido.

Dios guarde a usted

Firma: M. Cordero

\section{DOCUMENTO 20 -AGA- CAJA 15279}

Buenos Aires, febrero 19 de 1879

Al Sr. Jefe Superior de la isla de Martín García Coronel Don Donato Álvarez:

Sirva usted disponer se reciban en depósito en esa isla, los indios y chusma que conduce el vapor "Santa Rosa" a cargo del Teniente Coronel Herrera y Ayudante Mayor Denis.

En el mismo vapor remitirá usted todas las indias mujeres y chusma de los que anteriormente se mandaron a su parte, que se encuentran en condiciones de venir a esta ciudad.

Dios guíe a usted.

Firma Luís María Campos. Martín García,

Febrero 20 de 1879 
Acúsese recibo [ilegible], haberse recibido del Comandante Herrera y Ayudante Denis 98 indios - 120 chinas y 131 de chusma, y que se remiten a la Capital 63 chinas y 35 criaturas de las que se encontraban en depósito.

Firma: Matoso

DOCUMENTO 21 -AGA- CAJA 15279

Buenos Aires, febrero 4 de 1879

Al Jefe Superior de la isla de Martín García Coronel Don Donato Álvarez:

Sírvase usted disponer que de los indios Ranqueles que existen en depósito sean entregados diez indios al Coronel Martín Guerrico, con destino a la Armada Nacional, los cuales serán a elección de este jefe.

Dios guíe a usted.

Firma Luís María Campos

DOCUMENTO 22 -AGA- CAJA 15277

\section{NOTES}

1. Vale la pena recordar que, tras la batalla de Caseros que enfrentó al gobernador de la provincia de Entre Ríos (Justo José de Urquiza) con el de Buenos Aires (Juan Manuel de Rosas), se produjo la secesión de Buenos Aires del resto de la Confederación. Situación que se mantuvo hasta 1862.

2. El Tratado Internacional del Río de la Plata, firmado entre Uruguay y Argentina en 1973, (Capítulo VIII: Islas. Artículo 45), especifica que "La Isla Martín García será destinada exclusivamente a reserva natural para la conservación y preservación de la fauna y flora autóctonas, bajo jurisdicción de la República Argentina..." Sin embargo la isla como reserva natural provincial y recreo turístico comenzará a tener mayor difusión mediática tras el retorno a la democracia (1983) y el fin de la jurisdicción de la Armada Argentina en Martín García.

3. Convención para la Sanción y Prevención del Delito de Genocidio. Artículo 2º. 1948.

4. UBACYT-GEF 0129. Trayectorias de confinamiento, deportación y disciplinamiento de la población originaria en el contexto del genocidio indígena: Argentina 1870-1930; UBACyT F-810 "Memorias de Archivo sobre el Genocidio. Sometimiento e in-corporación indígena al estadonación”; PICT-2006-1591 "Genocidio, diáspora y etnogénesis indígena en la construcción del Estado Nación argentino".

5. Se entiende por Etnocidio o Genocidio Cultural a la destrucción intencional de una cultura por su per-tenencia a un grupo racial, étnico o religioso. Esta práctica no incluye, necesariamente, la destrucción de vidas. Las prácticas etnocidas se subdividen según la naturaleza de las mismas, pudiendo ser: a- Etnocidio Físico y Biológico (adopción de medidas que tiendan a generar tasas decrecientes de nacimientos; poner en peligro la salud de los grupos; crear condiciones de esclavitud; deportación sistemática; torturas y violaciones sexuales). b- Etnocidio Económico (destrucción de las bases y condiciones económicos de existencia) c- Etnocidio Lingüístico (prohibición del uso del lenguaje o destrucción intencional del lenguaje del grupo víctima) dEtnocidio Espiritual y Religioso (prohibición o disrupción severa de las prácticas religiosas). eEtnocidio Social (prohibición, censura o cualquier forma de restricción de la celebración y la continuidad de la memoria histórica) (Charny 1999).

6. Sólo para el periodo Diciembre de 1878- Marzo de 1879 se anotan más de 220 fallecidos indígenas. La mayor parte, por la epidemia de viruela. (AABA - Libro $1^{\circ}$ Defunciones, Capilla Martín García) véase también Copello (1944). 
7. Cabe señalar que durante este periodo, la isla también funciona como un centro de recepción de inmigrantes que, a modo preventivo, debían pasar un periodo de cuarentena en el lazareto. De esta manera y en consonancia con la problemática epidemiológica, las políticas de control higiénico son parte de las implementadas sobre los indígenas, y aunque no son exclusivas de los mismos mantienen ciertas especificidades en función del actor involucrado.

8. Carta al Comandante Militar de la Isla, de Luís María Campos. AGA. Caja 15283. 02/07/1883.

9. El Lazareto de Martín García funcionó principalmente para albergar a inmigrantes que realizaban la cuarentena dentro del mismo, sin embargo en diferentes oportunidades los documentos hacen mención del uso del mismo por parte de presidiarios e indígenas convalecientes; además de mencionar entre su personal a indígenas destinados en la isla.

10. En nota dirigida al entonces Coronel Luís Py desde la Inspección de Comandancia General de Armas en la temprana fecha del 22 de agosto de 1871, se solicita "lista de indios e indias que se hayan recibido en ese punto en diferentes remesas". AGA, caja 15272.

\section{ABSTRACTS}

This article aims to contextualize and analyze historical records in the Navy's General Archives (NGA). NGA documentation is mostly related to daily instructions and member's files. Of particular interest for our investigation were the historical sources regarding the indigenous concentration camp that took place in Martín García Island before, during and after the military campaigns on the territories of Pampa, Patagonia and Chaco.

Physical elimination and territorial dispossession practices have been complemented by strong policies of social deconstruction, family ties destruction, manpower alienation, cultural identity denial, forced redistribution, etc.

The following are the two central issues to be addressed when trying to explain the genocide mechanisms in this context: (a) the different ways of controls and physical exploitation in Martín García and (b) the methods used to distribute indigenous people.

This work's goal is to analyze the Argentinean genocide praxis through particular documents embedded in a major and longer social and historical process. These files are the evidence of the destination for those indigenous taken to the concentration camp in the island, but also of the systematic ways of abuse and control perpetrated in this genocide framework.

El siguiente trabajo contextualiza y analiza material del Archivo General de la Armada (AGA). Dicho repositorio posee gran cantidad de documentación relativa a instrucciones cotidianas y registro del personal de la Armada y, particularmente, fuentes sobre el accionar de la marina en Martín García con los indígenas allí concentrados durante los periodos previos, contemporáneos y posteriores a las campañas militares en Pampa, Patagonia y Chaco.

Las prácticas de eliminación física y despojo territorial fueron acompañadas por políticas de desestructuración social como la destrucción de lazos de parentesco, la enajenación de la fuerza de trabajo; la negación identitaria cultural, el reparto forzoso de los grupos sometidos, etc.

Hemos focalizado nuestro recorte temático en torno a dos cuestiones centrales a la hora de explicar parte de los mecanismos genocidas: (a) las formas de control y explotación física en la isla Martín García y (b) las formas de repartimiento y distribución de los indígenas sometidos.

El objetivo de este trabajo es observar la sistematicidad genocida del Estado argentino a través de un corpus que nos permite explicar aspectos particulares pero inherentes a un proceso socio- 
histórico de mayor envergadura. Se trata de registros y documentos estatales oficiales que dan cuenta no sólo del destino de parte de los indígenas concentrados; sino también de las formas sistemáticas de abusos y controles cometidos en el marco de este genocidio.

\section{INDEX}

Keywords: Indigenous Genocide, Martín García Island, Concentration Camp, Control and Distribution.

Palabras claves: Genocidio Indígena, Isla Martín García, Campo de concentración, Control y distribución

\section{AUTHORS}

\section{MARIANO NAGY}

Facultad de Filosofía y Letras. Universidad de Buenos Aires, Argentina.

Correo electrónico: marianonagy@yahoo.com.ar

\section{ALEXIS PAPAZIAN}

Facultad de Filosofía y Letras. Universidad de Buenos Aires -Consejo Nacional de Investigaciones Científicas y Técnicas (CONICET), Argentina.

Correo electrónico: alexis_papazian@yahoo.com.ar 